\title{
ETL
}

International Conference on Research in Education, Teaching and Learning

Paris, France| November 2 -4, 2018

\section{Between institutional requirements and classroom assessment practices: how to ensure coherence?}

\author{
Walther TESSARO \\ University of Geneva
}

\begin{abstract}
In curricula, the evaluative component is only rarely specified and it is therefore up to teachers to conceive instruments that make possible to evaluate students' learning. It is up to them to take responsibility for internal coherence in the alignment between school requirements, teaching content and assessed learning. Among new challenges of classroom assessment practices, elaboration and marking of complex tasks certainly represent for teachers ... a complex task, which highlights the professionalism of their judgment. What are the benchmarks that allow an informed decision? What do teachers do with dilemmas? To what adjustments do they proceed? Why does reality sometimes resist? Here are some questions that we will discuss in the light of our professional training experience and our research conducted in classrooms. Keywords: Assessment Practices, Alignment, Complex Tasks, Curricula.
\end{abstract}


